\title{
DEBATES
}

\section{A defesa do Estado social no Brasil e nos Estados Unidos da América}

\author{
The defense of the welfare State in Brazil and in the United States of \\ America
}

\section{Gilberto Soares Ferreira \\ Cícero Krupp da Luz}

\section{Resumo}

Este artigo analisa a relação entre o aumento da desigualdade no Brasil e nos Estados Unidos da América e a necessidade de um Estado social para o século XXI. Na primeira parte, estabelece-se uma relação entre a consolidação do neoliberalismo e a concentração da riqueza global. Na segunda parte, é feita a descrição da crise do Estado social nos dois países e são apresentadas as propostas de um Estado social para o século XXI. A definição da posição jurídica dos direitos sociais é analisada em conjunto com suas disputas políticas e econômicas, de forma interdisciplinar. Assim, a pesquisa guarda uma referência metodológica exploratória, ainda que se utilize de técnicas históricas e de uma perspectiva teórica marcadamente crítica. Os resultados apontam para uma diminuição da mediação do Estado social entre capital e trabalho. No entanto, estudos científicos e organizaçóes internacionais ainda sustentam que os direitos sociais são centrais para a redução da desigualdade neste século.

\section{Palavras-chave}

Desigualdade; Neoliberalismo; Estado Social.

\begin{abstract}
This paper analyses the connection between the increasing inequality in Brazil and in the United States of America and the need for a welfare State in the twenty first century. On the first part, the consolidation of neoliberalism and the concentration of global wealth are described. On the second part, the crisis of welfare State in both countries and the proposals for a welfare State for the twenty first century are described. The juridical status of social rights is presented with their economic and political disputes, in an interdisciplinary approach. Therefore, the research holds an exploratory methodology, but also uses historical techniques from a critical theory perspective. The results indicate that the mediation of welfare State between capital and labor is weakening. However, there are still scholars and international organizations that support social rights in order to reduce inequality in this new century.
\end{abstract}

\section{Keywords}

Inequality; Neoliberalism; Welfare State. 


\section{Introdução}

A presente pesquisa trata da relação entre o aumento da desigualdade no Brasil e nos Estados Unidos da América e a necessidade de um Estado social para o século XXI. Estudos descrevem as consequências da grande distância entre ricos e pobres que existe tanto nos chamados países centrais quanto nos periféricos. Atores do poder econômico conseguem determinar as pautas políticas, especialmente por meio do controle dos recursos públicos e da imposição de medidas de austeridade contra os trabalhadores.

Após a consolidação do neoliberalismo, a partir da década de 1980, o Ocidente presenciou crises sucessivas, mas também períodos de crescimento econômico e de desenvolvimento tecnológico. No entanto, eles não resultaram em benefícios permanentes para as populaçôes mais pobres. Ao contrário, atualmente existe um profundo quadro de desigualdade social no Ocidente. Mesmo nos chamados países desenvolvidos, são vários os estudos que comprovam o aumento da concentração do patrimônio e da renda. Os EUA e a Europa ainda sofrem os efeitos da crise do sistema financeiro, ocorrida em 2008. O Brasil, por sua vez, ainda está longe de cumprir seus objetivos constitucionais de redução das desigualdades. $\mathrm{O}$ aumento da desigualdade e a necessidade de um Estado social têm como variáveis explicativas a consolidação do neoliberalismo, como modelo econômico que promoveu concentração de riqueza, e a restrição de recursos orçamentários para os direitos sociais, como projeto de redução da intervenção do Estado na economia.

Embora existam importantes distinçóes entre os países estudados, por exemplo, quanto a aspectos econômicos e geopolíticos, a reuniáo destas realidades contribui para o debate sobre a desigualdade, seja a partir de questôes internas de cada país ou quando se trata do mundo globalizado. No âmbito interno, quando se analisam heranças históricas, é possível encontrar semelhanças, como são os desafios contemporâneos da população negra em ambos os países. $\mathrm{O}$ racismo, o direcionamento do aparato criminal repressivo, o encarceramento em massa e as maiores dificuldades para acesso a serviços públicos ou à assistência social são exemplos. Do ponto de vista internacional, a consolidação do neoliberalismo, especialmente a partir da década de 1980, significou, tanto na América Latina quanto nos EUA, a conjugação de uma financeirização da riqueza, o aumento de sua concentraçáo em uma parcela mínima da população e a redução da capacidade do Estado de garantir direitos sociais. A comparação, portanto, contribui para identificar elementos comuns acerca da desigualdade em países com desenvolvimentos econômicos muito distantes. 
Existem diferenças importantes entre as tradiçóes jurídicas dos dois países. No Brasil, parte dos direitos sociais foi promovida em períodos autoritários. A Constituiçáo Federal de 1988, por sua vez, estabelece uma série de direitos sociais, alguns regulamentados de forma detalhada em seu próprio texto. Os EUA, desde sua fundação, não registram governos autoritários ou o fechamento de suas instituições políticas, o que não impediu, no entanto, a violenta opressão de direitos civis, como ocorreu com as leis de segregação racial. Os direitos sociais foram criados ao longo de sua história sem a necessidade de uma previsão constitucional expressa. São diferenças que não impedem a comparação no presente estudo, pois as variáveis analisadas para a indicaçáo do aumento da desigualdade e da restrição de direitos sociais sáo verificadas em ambos os países. Os estudos sobre as consequências dos modelos econômicos que prevaleceram a partir de 1980 indicam o aumento da concentraçáo da riqueza e a captura de recursos orçamentários por uma pequena parcela da população.

A metodologia aplicada é a de revisão bibliográfica, e esta foi dividida em duas partes. $\mathrm{Na}$ primeira, estabelece-se uma relação entre a predominância do neoliberalismo, a partir da década de 1980, e o aumento da desigualdade, com a progressiva financeirizaçáo e concentraçáo da riqueza. Theotonio dos Santos (2016) analisa o conceito de neoliberalismo e seus efeitos na América Latina, em especial as restriçôes de direitos sociais e os problemas relacionados à dívida pública. Na segunda parte, é feita a descrição da crise do Estado social, das medidas de austeridade contra os trabalhadores nos dois países e das propostas de um Estado social para o século XXI. Direitos sociais são considerados como prestados direta ou indiretamente pelo Estado com o objetivo de melhorar as condiçôes materiais de vida dos cidadãos. São exemplos o direito à saúde, à educação e à seguridade social. Holmes e Sunstein (2019) negam a tradicional divisão entre direitos negativos e positivos, que concentra a crítica dos direitos sociais em seus custos. Defendem, ao contrário, que os direitos de bem-estar são um dever de governos democráticos.

Pretende-se uma análise interdisciplinar destes direitos. Autores que definem sua posição jurídica são analisados em conjunto com aqueles que tratam das disputas políticas e econômicas que envolvem o tema. A pesquisa guarda uma referência metodológica exploratória, ainda que se utilize de técnicas históricas e de uma perspectiva teórica marcadamente crítica. De forma náo definitiva, do ponto de vista institucional, os resultados apontam para uma diminuição da mediação do Estado social entre capital e trabalho. No entanto, estudos científicos e organizaçóes 
internacionais ainda sustentam que os direitos sociais são centrais para a redução da desigualdade neste século.

\section{Neoliberalismo e concentração de riqueza}

Um estudo sobre a desigualdade divulgado pelo Instituto de Pesquisa do Banco Credit Suisse (CREDIT SUISSES RESEARCH INSTITUTE, 2019) relatou que, até meados do ano de 2019 , metade da populaçáo mundial concentrava menos do que $1 \%$ da riqueza global. Por outro lado, os $10 \%$ mais ricos concentravam $82 \%$, e apenas $1 \%$ da populaçáo concentrava $45 \%$ da riqueza. Quanto a este último dado, chama a atenção o fato de que a concentração de riqueza nas mãos desta parcela de $1 \%$ sofreu um declínio até a crise financeira de 2008, e, após, elevou-se novamente até se estabilizar em 2016. Segundo relatório da OXFAM International (2018), enquanto bilhôes de dólares são pagos em bônus ou dividendos para altos executivos e acionistas, o trabalho é cada vez mais precarizado, com jornadas exaustivas, agressóes graves à saúde do trabalhador e salários que não os afastam da linha da pobreza. Além disso, a ideia frequentemente defendida de que as grandes fortunas são fruto de mérito ou talento pessoal é refutada:

O poder monopolístico é acentuado pelo compadrio - a capacidade de interesses privados poderosos de manipular políticas públicas no intuito de consolidar monopólios existentes e criar outros. Acordos de privatizaçóes, recursos naturais concedidos por valores muito abaixo do que seria justo, corrupção nas compras e contratos públicos ou isençôes fiscais e brechas jurídicas são todos mecanismos pelos quais interesses privados com relaçóes estreitas com o poder público podem enriquecer à custa do público em geral (OXFAM INTERNATIONAL, 2018, p. 9).

Soma-se a esses fatos a capacidade que essas elites possuem de evitar a taxação de suas riquezas pelos governos com remessas de valores para paraísos fiscais, prejudicando a arrecadação de impostos em seus países. No entanto, crimes financeiros não recebem a devida atenção das autoridades ou mesmo dos grandes meios de comunicação, seja pela dificuldade de apuração ou por interesses próprios dos que deles se beneficiam. Zaffaroni (2000) descreveu como a globalizaçáo se apoia nos mitos do equilíbrio natural do mercado internacional e na eficácia preventiva do poder punitivo nacional. No entanto, condutas como evasão de divisas, formação de oligopólios, alteraçóes artificiais de mercados e agressóes ao meio-ambiente ocorrem 
sem punições. A realidade não coincide com a norma (anomia generalizada), o que resulta no domínio dos delitos econômicos em nível planetário.

Nos EUA, a defesa contemporânea de direitos sociais insere-se em um contexto de crescente desigualdade. Piketty (2014) afirma que, desde os anos 19701980, ocorreu uma explosáo sem precedentes da desigualdade de renda no país. A parcela formada pelos $10 \%$ mais ricos da populaçáo possuía $50 \%$ da renda nacional em 2010. Estima-se que esta mesma parcela pode chegar a possuir $60 \%$ da renda nacional até 2030. O autor afirma que o aumento da desigualdade foi decisivo para a fragilizaçáo do sistema financeiro. A perda do poder de compra das classes populares e médias - somada com a oferta de crédito sem o devido controle pelos agentes intermediários, que buscavam altos rendimentos - resultou no endividamento das famílias mais pobres, o que contribuiu para o colapso de 2008. A alta da desigualdade da renda no país é explicada em grande parte pela desigualdade dos salários, como é o caso da relação entre os supersalários de executivos de grandes empresas e os trabalhadores em geral.

O relatório da Organização das Nações Unidas (ALSTON, 2018) sobre extrema pobreza e direitos humanos, após visita realizada nos Estados Unidos entre os dias $1^{\circ}$ e 15 de dezembro de 2017, descreve que, em comparação com os demais membros da Organizaçáo para Cooperação Econômica e Desenvolvimento (OCDE), o país possui a maior taxa de pobreza na juventude, com menor expectativa de vida e piores condiçóes sociais. Em 2016, 40 milhôes de pessoas tinham rendimentos abaixo da linha oficial de pobreza. Os EUA possuem, ainda, o maior índice de encarceramento e um dos níveis mais baixos de registro de eleitores. O relatório descreve a ausência de mobilidade social no país, com a pobreza sendo transmitida entre gerações. A igualdade de oportunidades e a visão do sonho americano se tornaram mitos, especialmente para mulheres e minorias, mas também para trabalhadores da classe média branca.

Com a consolidação do neoliberalismo a partir da década de 1980, surgem diversos estudos que defendem a relação entre suas propostas econômicas e o aumento da desigualdade mundial. Giddens (1996), ao diferenciar o velho conservadorismo, pautado pelos valores da hierarquia, da aristocracia e do sagrado, destacou a contradição de um novo conservadorismo, que pretende derrubar instituições como as do welfare state em vez de preservá-las, adotando inclusive o radicalismo. Hayek (2010) foi um representante dessa nova direita ao refutar a possibilidade de um bem-estar coletivo em uma escala única de valores, o que seria 
aprisionador. $\mathrm{O}$ individualismo, ao contrário, traria a liberdade de ação e os fins sociais seriam alcançados pela soma dos interesses dos indivíduos.

O neoliberalismo surgiu na América Latina ainda na década de 1970, em países como o Chile, mas "[...] ganhou impulso nos anos 1980 e atingiu o seu auge nos anos 1990, tornando-se predominante na regiáo com o estabelecimento do Consenso de Washington” (MARTINS, 2011, p. 313). Giffin (2007) traça uma síntese de seus efeitos: a redução de gastos públicos e a transferência de serviços públicos para o mercado; a flexibilização do mercado de trabalho e o enfraquecimento de organizaçóes trabalhistas; a desregulamentação dos mercados financeiros e dos controles sobre a moeda nacional.

Santos (2016) afirma que o neoliberalismo foi uma reação contra as conquistas sociais ocorridas nos países centrais no período pós-Segunda Guerra, bem como contra as lutas nacionais e democráticas que tiveram lugar nos países periféricos. As ideias de um grupo da Escola de Economia da Universidade de Chicago, reacionárias ao Estado de bem-estar social, ganharam cada vez mais adeptos entre os principais agentes do sistema financeiro mundial. No entanto, o início da efetivação dessas ideias na América Latina dependeria de governos autoritários, apoiados pelos governos militares e pelas oligarquias locais. $\mathrm{O}$ autor define $\mathrm{o}$ neoliberalismo como um pensamento liberal que remonta ao século XVIII e que se fundamenta em métodos já superados, como a existência de uma natureza humana cujo conceito é atrelado ao princípio do livre mercado:

O pleno funcionamento dessas características essenciais da natureza humana, se deixadas funcionar por um ambiente político e econômico liberal - composto pela liberdade econômica (o livre mercado), política (a democracia representativa) e de pensamento (o racionalismo instrumental) - permitiria a plena realização do ser humano, o progresso econômico e a felicidade. (SANTOS, 2016, p. 76).

A partir desses três elementos, é possível definir o neoliberalismo como uma proposta que se apoia: em uma economia liberal, com mínima ingerência do Estado nas relaçóes econômicas; em uma democracia limitada à representação e, portanto, ao processo eleitoral; e em um pensamento centrado no indivíduo que, através do empreendimento de sua razão, alcançaria seus objetivos. Ibarra (2011) destaca que as exigências neoliberais foram impostas nas relaçóes econômicas internacionais e sobre as decisóes políticas internas dos países ocidentais. Suas regras de eficiência econômica 
deveriam ser aplicadas pelos Estados com inibição da participação dos cidadãos, supostamente menos preparados para deliberar sobre essas questôes.

Soares (1998), em seu amplo estudo sobre as consequências dos ajustes neoliberais na América Latina, descreve seus impactos na economia. Os ajustes fiscais impostos aos Estados, a partir da década de 1970, provocaram o desequilíbrio das contas públicas e maior recessão econômica, atingindo inclusive o setor privado, $\mathrm{o}$ que resultou no aumento da taxa de desemprego e de informalidade. Por sua vez, a "[...] desregulação dos mercados financeiros e a abertura comercial irrestrita" (SOARES, 1998, p. 38) causaram instabilidades financeiras e cambiais em países como Chile, Argentina e México.

A questáo da dívida pública nos países latino-americanos é essencial para compreender as causas do subdesenvolvimento da regiáo e de sua submissão ao poder econômico internacional. Theotonio dos Santos (2016, p. 83) afirma que, no capitalismo atual, o capital financeiro internacional é um intermediário "[...] que recebe a maior parte do excedente nacional sob a forma de altos juros e outros mecanismos de expropriação dos valores produzidos por toda a população". Por sua vez, as intervençóes do Fundo Monetário Internacional e do Banco Mundial nos países emergentes são "[...] uma das heranças mais negativas do período hegemônico do neoliberalismo" (SANTOS, 2016, p. 101).

Ao identificar apenas alguns elementos do Estado de bem-estar social na América Latina, Soares (1998) destaca que as reformas neoliberais reduziram drasticamente as políticas sociais, com piora no funcionamento e cobertura dos programas. A flexibilização da legislação trabalhista diminui a inserçâo no trabalho formal e reduz a população protegida pela seguridade social. Quanto ao corte de gastos sociais defendido pelo pensamento neoliberal, a autora afirma que ele significa a retirada de recursos das instituiçóes públicas. Por outro lado, diversos estudos defendem que o problema da crise fiscal na América Latina não se deve a gastos sociais excessivos, mas ao problema da dívida pública.

Nos EUA, Mulloy (2018) descreve o importante apoio que Ronald Reagan, expoente do neoliberalismo no país, recebeu da Nova Direita (New Right) na década de 1980, com promessas de reduzir o governo, cortar impostos e a burocracia. Briggs (2017) relata que, no período, houve a retomada do conceito de "rainhas do bemestar" (welfare queens) para manchar a imagem de mulheres que eram apontadas como oportunistas das políticas assistenciais. 
A progressiva financeirização da economia é peça-chave para a compreensão dos efeitos do neoliberalismo na deterioração da economia produtiva e nos direitos de bem-estar. Chomsky (2008) descreve que, na década de 1950, o país era um grande centro industrial. As instituiçôes financeiras existiam, mas de forma regulada, deixando pouco espaço para especulação cambial. A partir da década de 1970, sistemas regulatórios de capitais, como o de Bretton Woods, foram desmantelados. Juntamente com a redução dos lucros no setor industrial, surge uma grande transformaçáo no sistema financeiro, com aumento da complexidade das operaçóes e dos investimentos de risco.

Com a adesão de grandes empresas a esses processos especulativos, o setor financeiro assume maior porção do PIB em relação ao setor industrial. Lupatini (2012) afirma que, no mesmo período, inicia-se o crescimento exponencial da dívida pública nos países desenvolvidos. Marx (2011) já havia descrito a questáo da dívida pública e seus efeitos na financeirização da riqueza:

A dívida pública converte-se numa das alavancas mais poderosas da acumulação primitiva. Como uma varinha de condão, ela dota o dinheiro de capacidade criadora, transformando-o assim em capital, sem ser necessário que seu dono se exponha aos aborrecimentos e riscos inseparáveis das aplicaçóes industriais e mesmo usurárias. Os credores do Estado nada dão na realidade, pois a soma emprestada converte-se em títulos da dívida pública facilmente transferíveis, que continuam a funcionar em suas mãos como se fosse dinheiro. A dívida pública criou uma classe de capitalistas ociosos, enriqueceu, de improviso, os agentes financeiros que servem de intermediários entre o governo e a nação. (MARX, 2011, p. 868).

Varoufakis (2016) faz uma minuciosa descrição da crise de 2008 e de como as agências de Wall Street foram omissas ou diretamente responsáveis pelo colapso financeiro. A especulação descontrolada, fundamentada em cálculos matemáticos complexos e sem compromisso com a realidade, resultou em uma crise econômica cujos efeitos persistem ao redor do mundo. $\mathrm{O}$ autor destaca o papel das chamadas "teorias econômicas tóxicas" (VAROUFAKIS, 2016, p. 151) e de como, posteriormente ao colapso financeiro, os EUA e o Reino Unido foram exemplos de países que, com o dinheiro dos contribuintes, injetaram recursos para resgatar os mesmos bancos e agentes responsáveis por essa quebra generalizada. 
Diante das sucessivas crises econômicas que decorrem desse cenário, duas medidas principais são adotadas pelos governos: o socorro às instituiçóes financeiras, com o dinheiro dos contribuintes, e planos de cortes dos direitos sociais, sob o antigo argumento de luta contra o big government. Sem considerar a contradição da defesa de um Estado mínimo que deve ser grande para socorrer os agentes do poder econômico, as doutrinas do livre mercado exigem a intensificação de medidas de austeridade contra os trabalhadores. No Brasil ou nos EUA, a diminuição do Estado social é justificada por restriçôes orçamentárias que escondem os desequilíbrios no acesso aos recursos públicos por diferentes atores.

\section{Desafios do Estado social no século XXI}

Existe uma ampla literatura sobre as definiçóes do welfare state e sobre seu modo de funcionamento. Garcia-Pelayo (2009) afirma que o Estado de bem-estar pode ser visto como a tentativa de adaptar o Estado liberal burguês à realidade da civilização industrial e pós-industrial. Não se trata de transformar sua estrutura, mas de reformá-la para melhorar as condiçôes gerais de vida da população mais pobre. No campo das relaçôes econômicas, a atuação do Estado deixa de ser subsidiária para ser direta, com tendência a uma "política estatal de direção". Essa ampla função de direção do Estado surge no contexto das crises causadas pelas grandes guerras e foi possível pelo desenvolvimento científico e tecnológico, que permitiu a planificação e racionalização dos sistemas sociais.

Diante da necessidade de mobilização da sociedade e da economia, "[...] o papel ampliado do Estado na Primeira Guerra introduziu formas de provisão social e econômica que foram solidificadas e ampliadas durante a Segunda" (GIDDENS, 1996, p. 155). O autor aponta como fontes estruturais do welfare state: a criaçáo de uma sociedade na qual o trabalho assalariado tivesse um papel central; a relação entre este sistema e a solidariedade nacional, consolidada no Estado-Nação; a administração de riscos futuros em uma sociedade criadora de riquezas. A expansão do welfare state, a partir da década de 1950, passando a buscar a universalidade, foi explicada pelo sentimento, após a Segunda Guerra Mundial, de que os riscos da sociedade poderiam atingir todos seus integrantes. Em consequência, surgiu uma maior propensão coletiva de contribuir com esse modelo.

Esping-Andersen (1990) indica como principal debate contemporâneo sobre o welfare state a possibilidade de as democracias parlamentares reduzirem as desigualdades produzidas pelo capitalismo e as condiçôes para tanto. Offe (1995) 
delimita três elementos básicos que integram o Estado de bem-estar social nas democracias liberais: a soberania do poder estatal, a limitação formal do Estado por meio dos direitos individuais e as prestaçôes de serviços públicos. Os cidadáos, por um lado, formam a vontade política, se submetem a ela, mas também limitam o Estado a partir dos direitos e liberdades civis. Por outro, são os destinatários de programas coletivos que garantem bem-estar material, social e cultural.

Esping-Andersen (1990) descreve o regime de bem-estar nos Estados Unidos como um welfare state do tipo liberal, com transferências e seguros sociais modestos. Os benefícios são direcionados principalmente para trabalhadores de baixa renda, que dependem do auxílio do Estado. Tradicionalmente ligado a uma ética normativa do trabalho, possui normas mais rigorosas e os valores dos benefícios são baixos. $\mathrm{O}$ Estado também encoraja o mercado, por meio de subsídios, a fornecer estruturas de welfare. $\mathrm{O}$ autor utiliza o conceito de "desmercadorização (de-commodification)" (ESPING-ANDERSEN, 1990, p. 21) da força de trabalho como a possibilidade, em alguns tipos de Estado social, de o trabalhador conseguir manter um nível aceitável de vida, independentemente das condiçóes do mercado. No caso dos Estados Unidos, o conjunto de regras para a obtençáo dos benefícios minimiza este efeito, reforçando a estratificação da sociedade.

A diversidade de compreensóes sobre a estrutura do welfare state também é vista na explicação de sua crise. $\mathrm{O}$ neoliberalismo é visto como o marco que fundamenta o repúdio à intervenção do Estado na economia. $\mathrm{O}$ crescimento da riqueza financeira acompanha os ataques a direitos trabalhistas, sociais e aos postulados do Estado de bem-estar social (MUSTAFÁ, ANSELMO e SILVA, 2018). Offe (1995) explica como, em alguns países democráticos, ocorreu, do ponto de vista dos eleitores, o progressivo abandono da ideia de um Estado de bem-estar. A partir da década de 1970, passou a ocorrer uma fragmentaçáo de coletividades, como era o caso das organizaçôes de classe dos trabalhadores. O fim dessas comunidades de interesses - que compartilhavam laços culturais, econômicos e estilos de vida - fez com que se enfraquecesse uma solidariedade social que sustentava o compromisso com direitos coletivos. Quando estas referências comuns desaparecem, os indivíduos passam a pensar em si mesmos de uma forma "racional-calculista", algo que pode ser aproveitado pelo populismo de direita. Enquanto a expansáo do welfare state depende de uma ampla coalizão política e de mobilização de massas, sua redução pode ocorrer em razão de pressóes econômicas e orçamentárias quando inexiste um sistema de alianças suficiente para mantê-lo. 
Fernández (2019) destaca consequências econômicas e políticas da crise deste modelo. No Estado social, os direitos sociais eram complementares aos salários. Eram prestaçóes que permitiam que o trabalhador direcionasse seus rendimentos ao consumo, aumentando a demanda. Os processos democráticos serviram para mediar a relação entre capital e trabalho em um contexto de revoluçóes e resistências organizadas pelos trabalhadores. No entanto, a partir da financeirização da riqueza, a especulação toma o lugar da produção; o consumo deixa de ter como origem principal o salário e passa a priorizar o endividamento, que rende juros aos credores. $\mathrm{O}$ enfraquecimento das identidades de classe e a precarização do trabalho reduziu as resistências e, em consequência, as instâncias de mediação política.

Com relação aos direitos sociais, existem diferenças importantes entre as tradiçóes jurídicas do Brasil e dos EUA. No Brasil, parte destes direitos foi promovida em períodos autoritários, durante o Estado Novo de Getúlio Vargas e durante a ditadura militar. A Constituição Federal de 1988, por sua vez, estabelece uma série de direitos sociais, alguns regulamentados de forma detalhada em seu próprio texto. Nos EUA, estes direitos foram consolidados ao longo de sua história, sem a necessidade de uma previsão constitucional expressa.

A Constituição de 1988 foi o resultado de um conjunto de movimentos sociais que trouxe a perspectiva de uma definitiva consolidação da democracia no país, com objetivos de redução de desigualdades e de desenvolvimento econômico. Os direitos sociais previstos expressamente na Constituição são tradicionalmente compreendidos, pela pesquisa do direito constitucional, como necessários para a redução das desigualdades:

São, portanto, direitos que se ligam ao direito de igualdade. Valem como pressupostos do gozo dos direitos individuais na medida em que criam condições materiais mais propícias ao auferimento da igualdade real, o que, por sua vez, proporciona condição mais compatível com o exercício efetivo da liberdade. (SILVA, 2009, p. 288).

Streck e Morais (2012), por sua vez, defendem o papel do Estado como agente principal da política social, especialmente em países onde o Estado social de fato não existiu. Segundo os autores, o neoliberalismo, que defende um Estado mínimo, não tem como essência a realização desta tarefa. A defesa de um Estado que se abstém da missáo de reduzir as desigualdades é contrária ao ordenamento constitucional brasileiro. A intervenção e regulação de um Estado forte integra o que 
se conhece como Estado Democrático de Direito. O Direito, portanto, é local de luta para a implementaçáo dessas promessas não cumpridas, juntamente com as lutas políticas realizadas junto ao executivo e ao legislativo.

Sarlet (2015) descreve que a exigibilidade dos direitos sociais encontra um de seus limites na literatura jurídica na chamada reserva do possível, que é definida a partir de três elementos: a disponibilidade fática do recurso; a disponibilidade jurídica do recurso, que envolve questôes de competência para sua execução, especialmente em um sistema federativo; e a proporcionalidade e razoabilidade de sua execuçáo, considerando-se o titular do direito pretendido. Já a manutenção desses direitos encontra proteção no chamado princípio da vedação do retrocesso, embora ele venha acompanhado de todas as discussóes a respeito do que seria um núcleo essencial constitucional protegido contra a redução ou eliminação pelo legislador infraconstitucional. Canotilho (2010) descreve que as teses que afirmam a inviabilidade do Estado social fundamentam-se na existência de um mercado global, que pressiona os governos nacionais a atrair investimentos e a reduzir despesas, além da dificuldade de evitar a fuga de capitais, o que reduz a arrecadaçáo de receitas.

Todas estas questôes trazem como pano de fundo o que talvez seja a grande oposiçáo contra a concretizaçáo de direitos sociais, que é a insuficiência de recursos orçamentários. Ela embasa a adoção por diversos governos de medidas como cortes de recursos e extinção de órgãos e de programas de proteçáo social, que afetam amplos setores da classe trabalhadora. No entanto, esse argumento esconde pressóes do poder econômico sobre o fundo público que ficam fora do debate democrático. É importante analisar, portanto, como os direitos sociais são preteridos em favor dos interesses de uma minoria ou mesmo relativizados como direitos fundamentais em razão do seu custo para a sociedade. Trata-se, portanto, de uma conjugação entre direito e a política (CORREIA, 2010).

Conforme descrito na análise do neoliberalismo na América Latina, a crise fiscal dos Estados não tem origem em gastos excessivos com direitos sociais, mas surge em razão do problema da dívida pública, que serve de instrumento para o capital financeiro internacional expropriar a maior parte do excedente nacional. Destaca-se que, desde a década de 1990, a liberalização e desregulamentação dos fluxos de capital no país produzem uma valorizaçáo do capital direcionada para o mercado de açóes. Esse processo acaba por direcionar o Estado a tomar medidas em prol desta forma de valorização do capital, em detrimento dos direitos da classe trabalhadora. Os principais detentores dos títulos federais são bancos nacionais e estrangeiros, fundos de investimento e entidades de previdência complementar (LUPATINI, 2012). 
A disputa por recursos públicos para o financiamento de direitos sociais tornou-se mais acentuada durante os governos pós-impeachment de 2016 no Brasil, com uma política agressiva de retração de direitos. A emenda constitucional 95 (BRASIL, 2016) é descrita como uma imposição econômica antidemocrática, uma vez que impede a expansão e a manutenção de políticas públicas, favorecendo os credores da dívida pública (MARIANO, 2017). Também é vista como o resultado de um confronto ideológico que ocorre durante governos que realizam investimentos em políticas sociais. Nos momentos de crise do capital, as políticas econômicas que prevalecem são as que sacrificam os direitos dos trabalhadores (MUSTAFÁ, ANSELMO e SILVA, 2018). A austeridade promove um círculo vicioso, pois a reduçáo de gastos do governo provoca a diminuição da renda do setor privado, que resulta na diminuição da arrecadação e, então, em nova exigência de cortes de gastos (ROSSI e DWECK, 2016).

Nos EUA, ao tratar da distinção entre constituiçôes pragmáticas e expressivas, Sunstein (2004) destaca que a previsão constitucional de direitos sociais como aspiraçôes ou metas náo combina com o pragmatismo da constituição dos Estados Unidos. No entanto, Holmes e Sunstein (2019) discordam da tradicional distinção entre direitos negativos, que dependeriam somente de uma abstençáo estatal, como os direitos de liberdade, e direitos positivos, como os direitos sociais, que dependeriam de prestaçôes estatais. Ambos os direitos dependem de uma ampla estrutura do Estado para serem garantidos. Sendo assim, os autores afirmam náo existir uma diferença significativa se os direitos sociais são garantidos por uma carta constitucional ou por uma legislação infraconstitucional, na medida em que o grau de proteção desses direitos será consolidado, em ambos os casos, na esfera política. Defendem, ainda, que os direitos de propriedade estejam vinculados aos direitos de bem-estar, como objetivo de um governo democrático.

Após as eleiçóes de 2016 nos EUA, a ONU (ALSTON, 2018) descreve mudanças drásticas nas políticas do novo governo, entre elas: o corte de impostos aos mais ricos e às grandes corporaçôes, financiado em parte pela redução de gastos com benefícios sociais para os mais pobres; desregulamentaçôes nas áreas de saúde e segurança, que afetam as classes média e baixa, podendo resultar na retirada de 20 milhôes de pessoas da cobertura de seguros de saúde; restriçóes dos potenciais beneficiários de políticas sociais e obstacularização dos requisitos para quem já os recebe; e ausência de medidas que reduzam o racismo estrutural, o que deixa uma 
parcela grande da populaçáo náo branca vivendo na pobreza ou próxima da linha da pobreza.

Os efeitos históricos da escravidão e da segregação racial permanecem e são percebidos na questáo do encarceramento em massa dos afro-americanos. Alexander (2017) descreve o cenário em que um milhão de negros estão presos no país. Grande parte deles em razão da guerra às drogas promovida ao longo de décadas. A autora questiona o discurso do progresso racial, uma vez que o número de afro-americanos presos é o maior da história, e afirma que a discriminação que estes cidadãos sofrem em consequência do aparato repressivo do Estado e de seus registros criminais assemelha-se a um novo Jim Crow ${ }^{\text {. }}$.

Por este motivo, a ONU (ALSTON, 2018) recomenda que o país interrompa a criminalizaçáo da pobreza, que ocorre com o encarceramento de moradores de rua, minorias acusadas de tráfico de drogas, pessoas com doenças mentais etc. A política de aprisionamento serve apenas para esconder problemas sociais. As prisóes realimentam a pobreza, na medida em que seus egressos não conseguem se inserir novamente na sociedade. Os registros criminais são obstáculos para encontrar trabalho e ter acesso a benefícios sociais. Famílias são destruídas e crianças ficam sem os pais. O relatório alerta que é a pobreza que deve ser atacada, náo os pobres.

Pesquisa realizada pelo Instituto Brookings (2019) relata que, nos EUA, 53 milhóes de pessoas (44\% dos trabalhadores entre 18-64 anos) exercem atividade de baixa-renda. Eles recebem em média, por hora, 10 dólares e 22 centavos e, anualmente, 17.950 dólares. Enfrentam essa situação 63\% dos trabalhadores latinos ou hispânicos; $54 \%$ dos trabalhadores negros; $40 \%$ dos trabalhadores asiáticos e 37\% dos trabalhadores brancos. Quanto ao direito à saúde, Stiglitz (2016) defende que ele deve ser acessível e universal. As forças do mercado não conseguem controlar os preços e oferecer serviços de qualidade para muitos. O resultado de um setor direcionado pelo mercado é que os cidadãos nos EUA pagam preços maiores pela saúde do que em outros países avançados.

A viabilidade de um Estado social no século XXI é um debate que movimenta diversas áreas do conhecimento. Piketty (2014) destaca que o papel do Estado no século XXI se tornou muito maior e mais complexo do que em 1930. Além disso, não se pode esperar uma expansão do Estado social na forma como ocorreu entre as décadas de 1930 e 1980, em razão das diferenças de conjunturas econômicas. O

\footnotetext{
${ }^{1}$ Conjunto de leis estaduais e locais que instituiu a segregação racial nos EUA e durou cerca de cem anos, até 1968 (HISTORY CHANNEL, 2019).
} 
acesso à saúde, educação e aposentadorias públicas foi uma verdadeira revolução social no século XX. O autor defende, entâo, um controle do sistema financeiro e a modernização da arrecadaçáo e de gastos, ou seja, aprimorar e não acabar com o Estado social. Um exemplo seria através de formas inovadoras, descentralizadas e participativas de governança. A OXFAM International (2018) pede aos governos que promovam regulaçóes que permitam maior poder de negociação dos empregados; empreendimentos com formas cooperativas e participação acionária dos trabalhadores; negócios que incluam em seus resultados a geração de benefícios sociais; regulação tributária para acabar com a riqueza extrema; oferta de serviços públicos gratuitos e um piso de proteção social.

\section{Considerações finais}

$\mathrm{O}$ presente estudo buscou estabelecer uma relação entre o aumento da desigualdade no Brasil e nos Estados Unidos da América e a defesa de um Estado social no século XXI. Foi descrito um cenário que conjuga, de um lado, a consolidação do neoliberalismo e, de outro, a restriçáo de direitos sociais, por meio da redução da capacidade do Estado de promover estes direitos.

O neoliberalismo é visto como uma reação ao Estado de bem-estar, promovido pelos economistas da escola de Chicago, com experiências na América Latina, ainda na década de 1970, tornando-se predominante na década de 1980 nos EUA com Ronald Reagan. Suas regras promoveram a desregulamentação dos mercados financeiros e uma defesa mais agressiva de um Estado mínimo; a intervenção estatal na economia passou a ser vista como uma intervenção indevida nas liberdades individuais. Embora o Ocidente tenha experimentado períodos de crescimento sob as políticas neoliberais, estudos sobre a desigualdade apontam que uma parcela mínima da população mundial se apropriou da maior parte riqueza global.

Semelhanças entre os países foram constatadas. Elas se fundamentam, essencialmente, na defesa das regras do mercado para a direção de políticas públicas. No Brasil, as reformas são justificadas por razões orçamentárias, embora não haja um debate amplo com a sociedade sobre o tema. O novo regime fiscal imposto pela emenda constitucional 95, de 2016, traz uma redução drástica nos investimentos sociais, enquanto a maior parte do orçamento é destinada para o serviço da dívida pública. Nos Estados Unidos, cortes de impostos para grandes corporaçóes ameaçam a arrecadação e, consequentemente, justificam novas medidas de austeridade contra 
os programas sociais. A redução de programas sociais e de serviços públicos é contestada por pesquisas sobre o tema e por organizaçóes internacionais. O país também registra um grande número de cidadáos em empregos precários e de baixarenda.

Em ambos os países, as consequências da escravidáo permanecem na desigualdade econômica, no preconceito contra os beneficiários da assistência social, na opressão estatal e no encarceramento em massa. A distinção tradicional entre direitos positivos e negativos pode disfarçar escolhas que ocorrem dentro das disputas políticas pelos direitos sociais. Outros estudos aprofundados são necessários, mas os custos das instituiçóes que defendem determinados direitos podem ser um indicativo de quais, ao contrário, estão sendo interditados. Os direitos sociais, portanto, estão inseridos em disputas políticas que permitem que algumas normas sejam concretizadas e outras postergadas.

Vive-se um momento em que a escassez de recursos básicos ameaça a própria sobrevivência humana. A mediação entre capital e trabalho, feita pelo Estado social por meio de instâncias democráticas, parece estar enfraquecendo. A pressão dos agentes econômicos sobre o poder político consegue definir prioridades dos recursos públicos em benefício de uma minoria. No entanto, ainda existem propostas importantes para um Estado social no século XXI: uma economia mais voltada à produção e à geraçáo de trabalho e renda e menos à especulação financeira; a consolidação de direitos sociais básicos e universais; o maior poder de negociaçáo dos trabalhadores; o fim do encarceramento em massa e da criminalização da pobreza.

A pesquisa náo pretendeu esgotar o problema, tendo em vista a necessidade de estudos mais aprofundados sobre, por exemplo, a relação entre capital e trabalho nas próximas décadas e sobre quais serão os modelos de Estado social adequados ao século XXI. No entanto, a persistência desta defesa é uma pauta que pode reunir mais pessoas e organizaçóes, formando um consenso mínimo necessário em um momento de incertezas e de ausência de projetos que tenham um potencial de mudanças radicais nas estruturas da desigualdade.

- Gilberto Soares Ferreira é Mestrando em Constitucionalismo e Democracia, pela Faculdade de Direito do Sul de Minas (FDSM). Analista Judiciário junto ao Tribunal Regional Eleitoral de Minas Gerais. E-mail: gilbertoferreirabr@yahoo.com.br. 
- Cícero Krupp da Luz é Doutor em Relações Internacionais, pela Universidade de São Paulo (USP). Professor da Graduação e do Mestrado em Constitucionalismo e Democracia da FDSM e de Relações Internacionais e de Ciências Econômicas na Fundação Escola de Comércio Álvares Penteado (FECAP). E-mail: ciceroluz@gmail.com.

\section{Referências}

ALEXANDER, Michelle. A nova segregação: racismo e encarceramento em massa. Tradução de Pedro Davoglio. São Paulo: Boitempo, 2017.

ALSTON, Phillip. United Nations. Report of the Special Rapporteur on extreme poverty and human rights on his mission to the United States of America. 04 maio 2018. Disponível em: <https://digitallibrary.un.org/record/1629536>. Acesso em: em 25 set. 2019.

BRASIL. Emenda Constitucional 95, de 15 de dezembro de 2016. Altera o Ato das Disposiçôes Constitucionais Transitórias, para instituir o Novo Regime Fiscal, e dá outras providências. Brasília, DF: Presidência da República, 2016. Disponível em: <http://www.planalto.gov.br/ccivil_03/constituicao/emendas/emc/emc95.htm>. Acesso em: 14 ago. 2020.

BRIGGS, Laura. How all politics became reproductive politics. From welfare reform to foreclosure to Trump. Oakland-CA: University of California Press, 2017.

BROOKINGS. Metropolitan Policy Program. 53 million U.S. workers are making low wages, despite low national unemployment. 07 de novembro de 2019. Disponível em: <https://www.brookings.edu/wp-content/uploads/2019/11/201911_Brookings-

Metro_Pressrelease_lowwageworkforce.pdf>. Acesso em: 30 jan. 2020.

CANOTILHO, J. J. Gomes. O direito constitucional como ciência de direcção - o núcleo essencial de prestaçóes sociais ou a localização incerta da socialidade (contributo para a reabilitação da força normativa da "constituiçáo social". In: CANOTILHO, J. J. Gomes;

CORREIA, Marcus Orione Gonçalves; CORREIA, Érica Paula Barcha (Coords.). Direitos Fundamentais Sociais. São Paulo: Saraiva, 2010.

CHOMSKY, Noam. Réquiem para o sonho americano: os dez princípios de concentração de riqueza e poder. Tradução de Milton Chaves de Almeida. 3. ed. Rio de Janeiro: Bertrand Brasil, 2008.

CORREIA, Marcus Orione Gonçalves. Interpretaçáo dos direitos fundamentais sociais, solidariedade e consciência de classe. In: CANOTILHO, J. J. Gomes; CORREIA, Marcus Orione Gonçalves; CORREIA, Érica Paula Barcha (Coords.). Direitos Fundamentais Sociais. São Paulo: Saraiva, 2010. 
CREDIT SUISSE RESEARCH INSTITUTE. Global Wealth Report. Out. 2019. Disponível em: $<$ https://www.credit-suisse.com/about-us/en/reports-research/global-wealth-report.html>. Acesso em: 07 nov. 2019.

ESPING-ANDERSEN, Gosta. The three worlds of welfare capitalism. Cambridge, UK: Polity Press, 1990.

FERNÁNDEZ, Albert Noguera. El desmonte de la constitución democrática: auge y formas de los neofascismos. In: GUAMÁN, Adoración; ARAGONESES, Alfons; MARTÍN, Sebastián (Dirs.). Neofascismo. La bestia neoliberal. Madrid: Siglo XXI de España, 2019.

GARCIA-PELAYO, Manuel. As transformaçôes do Estado contemporâneo. Tradução de Agassiz Almeida Filho. Rio de Janeiro: Forense, 2009.

GIDDENS, Anthony. Para além da esquerda e da direita. O futuro da política radical. Tradução de Alvaro Hattnher. São Paulo: Universidade Estadual Paulista, 1996.

GIFFIN, Karen Mary. Financeirização do Estado, erosão da democracia e empobrecimento da cidadania: tendências globais? Ciênc. saúde coletiva, v. 12, n. 6, p. 1491-1504, dez. 2007.

HAYEK, Friedrich A. O caminho da servidão. São Paulo: Instituto Ludwig von Mises Brasil, 2010.

HISTORY CHANNEL. Jim Crow Laws. 13 mar. 2019 [atual.]. Disponível em: <https://www.history.com/topics/early-20th-century-us/jim-crow-laws>. Acesso: 13 dez. 2019

HOLMES, Stephen; SUNSTEIN, Cass R. O custo dos direitos: por que a liberdade depende dos impostos. Tradução de Marcelo Brandão Cipolla. São Paulo: WMF Martins Fontes, 2019.

IBARRA, David. O neoliberalismo na América Latina. Revista de Economia Política, v. 31, n. 2, p. 238-248, abr./jun. 2011.

LUPATINI, Márcio. Crise do capital e dívida pública. In: SALVADOR, Evilasio et al. (Orgs.). Financeirização, fundo público e política social. São Paulo: Cortez, 2012.

MARIANO, Cynara Monteiro. Emenda constitucional 95/2016 e o teto dos gastos públicos: Brasil de volta ao estado de exceção econômico e ao capitalismo do desastre. Investigaçóes constitucionais, v. 4, n. 1, p. 259-281, jan./abr. 2017.

MARTINS, Carlos Eduardo. Globalização, dependência e neoliberalismo na América Latina. São Paulo: Boitempo, 2011.

MARX, Karl. O Capital. Crítica da economia política. Tradução de Reginaldo Sant'Anna. 25. ed. Rio de Janeiro: Civilização Brasileira, 2011. (Livro Primeiro. O processo de produção do capital, v. II).

MULLOY, Darren J. Enemies of the state. The Radical Right in America from FDR to Trump. London: Rowman \& Littlefield Publishers, 2018.

MUSTAFÁ, Maria Alexandra da Silva Monteiro; ANSELMO, Gisele Caroline Ribeiro; SILVA, Salyanna de Souza. Democracia e justiça social em tempos de golpe sob a égide do neoliberalismo. Katálysis, v. 1, n. 2, p. 416-426, maio/ago. 2018.

OFFE, Claus. Capitalismo desorganizado. 2. ed. 1. reimp. Tradução de Wand Caldeira Brant. Revisão da tradução: Laura Teixeira Motta. São Paulo: Brasiliense, 1995.

OXFAM INTERNACIONAL. Recompensem o trabalho, não a riqueza. 25 jan. 2018. Disponível em: <https://oxfam.org.br/projetos/recompensem-o-trabalho-nao-a-riqueza/>. Acesso em: 25 set. 2019.

PIKETTY, Thomas. O capital no século XXI. Tradução de Monica Baumgarten de Bolle. Rio de Janeiro: Intrínseca, 2014. 
ROSSI, Pedro; DWECK, Esther. Impactos do novo regime fiscal na saúde e educação. Cad. Saúde Pública, v. 32, n. 12, p. 1-5, 2016.

SANTOS, Theotonio dos. Desenvolvimento e civilização: homenagem a Celso Furtado. Rio de Janeiro: EdUERJ, 2016.

SARLET, Ingo Wolfgang. A eficácia dos direitos fundamentais: uma teoria geral dos direitos fundamentais na perspectiva constitucional. 12. ed. rev. atual e ampl. Porto Alegre: Livraria do Advogado, 2015.

SILVA, José Afonso da. Curso de Direito Constitucional Positivo. 32. ed. rev. e atual. São Paulo: Malheiros, 2009.

SOARES, Laura Tavares Ribeiro. Ajuste neoliberal e desajuste social na América Latina. Rio de Janeiro: UFRJ, 1998.

STIGLITZ, Joseph E. Rewriting the rules of the American economy. An agenda for growth and shared prosperity. New York: W. W. Norton \& Company, 2016.

STRECK, Lenio Luiz; MORAIS, José Luis Bolzan de. Ciência Política e Teoria do Estado. 7. ed., 2. tir. Porto Alegre: Livraria do Advogado, 2012.

SUNSTEIN, Cass R. The Second Bill of Rights. FDR's unfinished revolution and why we need it more than ever. New York: Basic Books, 2004.

VAROUFAKIS, Ianis. O minotauro global: a verdadeira origem da crise financeira e o futuro da economia global. Tradução de Marcela Werneck. São Paulo: Autonomia Literária, 2016.

ZAFFARONI, Eugenio Raúl. La globalización y las actuales orientaciones de la política criminal. In: PIERANGELI, José Henrique (Coord). Direito Criminal. Belo Horizonte: Del Rey, 2000. 